University of Nebraska - Lincoln

DigitalCommons@University of Nebraska - Lincoln

Faculty Publications: Department of Teaching, Department of Teaching, Learning and Teacher Learning and Teacher Education

Education

2011

\title{
What Makes the Anthropology of Educational Policy Implementation "Anthropological" ?
}

\author{
Edmund T. Hamann \\ University of Nebraska-Lincoln, ehamann2@unl.edu \\ Lisa Rosen \\ University of Chicago, rosen@uchicago.edu
}

Follow this and additional works at: https://digitalcommons.unl.edu/teachlearnfacpub

Part of the Educational Administration and Supervision Commons, Education Policy Commons, Policy History, Theory, and Methods Commons, Social and Cultural Anthropology Commons, Social and Philosophical Foundations of Education Commons, and the Teacher Education and Professional Development Commons

Hamann, Edmund T. and Rosen, Lisa, "What Makes the Anthropology of Educational Policy Implementation "Anthropological" ?" (2011). Faculty Publications: Department of Teaching, Learning and Teacher Education. 108.

https://digitalcommons.unl.edu/teachlearnfacpub/108

This Article is brought to you for free and open access by the Department of Teaching, Learning and Teacher Education at DigitalCommons@University of Nebraska - Lincoln. It has been accepted for inclusion in Faculty Publications: Department of Teaching, Learning and Teacher Education by an authorized administrator of DigitalCommons@University of Nebraska - Lincoln. 
Published (as Chapter 27) in A Companion to the Anthropology of Education, First Edition, edited by Bradley A. U. Levinson and Mica Pollock (Chichester: Wiley-Blackwell, 2011), pp. 461-477.

Copyright @ 2011 Blackwell Publishing Ltd. Used by permission.

\title{
What Makes the Anthropology of Educational Policy Implementation "Anthropological"?
}

\author{
Edmund T. Hamann \\ University of Nebraska-Lincoln
}

Lisa Rosen

University of Chicago

\begin{abstract}
The study of policy, therefore, leads straight into issues at the heart of anthropology: norms and institutions; ideology and consciousness; knowledge and power; rhetoric and discourse; meaning and interpretations; the global and the local - to mention but a few.
\end{abstract}

(Shore and Wright, 1997: 4)

As sociocultural theorists (e.g., Gutiérrez and Rogoff, 2003; Orellana, 2009) have recently asserted, "culture" is something one does, rather than something one has. That is, human beings produce, perform, and reproduce culture every day. Policy implementation - or what Milbrey McLaughlin (1987: 175) has called "muddling through" - is deeply implicated in these processes of cultural production and thus invites anthropological inquiry. Indeed, it is possible to link the study of policy implementation to some of the foundational efforts of anthropology, particularly cultural anthropology (Wedel et al., 2005). Our discussion in this chapter thus borrows explicitly and centrally from an early, classic cultural anthropology work (Malinowski, 1922), while also drawing on more recent research, to explain the distinctive characteristics of the anthropological study of policy implementation and its foundational analytic categories and concerns.

In 1984, Frederick Erickson updated and republished an essay titled, "What Makes School Ethnography 'Ethnographic?," which was initially published in 1973. Both ver- 
sions built centrally from Malinowski. Although "anthropological" and "ethnographic" are overlapping rather than synonymous terms, as are "school" and "educational policy implementation," Erickson's (1984) essay provides a highly useful template for our current endeavor. Its usefulness derives not only from his demonstration of how classical anthropological concepts can be applied to the study of education, but also because its very structure can be imitated here with the same questions posed about educational policy implementation that Erickson posed about the ethnography of schools. Erickson's chapter, however, is not as explicit about another concern - validity - so for consideration of that we also turn later in the paper to other sources, particularly Maxwell (1992).

Like Erickson (1984), we are writing at a time when the subfield we are describing in our case, educational policy implementation studies - is becoming increasingly wellestablished (see Datnow and Park, 2009; Honig, 2006; McLaughlin, 1987) and drawing many of its core methods and assumptions from anthropology, but not always acknowledging those roots explicitly (e.g.. Stein, 2004). Whether its anthropological components are overtly recognized or not, the subfield of educational policy implementation studies differs from the traditionally dominant field of educational policy studies. Thus, a modest purpose of this chapter is to clarify the anthropological components of educational policy implementation studies, but a larger one is to clarify how such inquiry differs more substantially from the dominant strains of educational policy research. Recently, Erickson and Gutierrez wrote, "A logically and empirically prior question to 'Did it work?' is 'What was the "it"?' - 'What was the "treatment" as actually delivered?'" (2002: 21). Studying the "it" as well as the outcomes (instead of outcomes only) is not the only distinction between anthropological education policy implementation studies and traditional educational policy studies, but it is an important one, and one that we return to throughout this chapter.

Like Erickson (1984), we face the task of adapting the original impulses of our discipline - to document cultures - for different purposes. However, unlike that historic (and subsequently critiqued) impulse of documenting a people who supposedly existed in a bounded, coherent, and relatively homogeneous collective, anthropological studies of education policy implementation cannot presume a single people or type as their target. Instead, they necessarily include explaining the heterogeneous bases for the interaction of diverse peoples through policy implementation. Policy implementation links people who often are obviously quite different from each other in terms of age, formal preparation, expected agency (as subject or object of implementation), location, and formal position, but who nonetheless are connected to one another as part of a web or network of social activity focused on: (1) defining (or contesting others' definitions of) what is problematic in education; (2) promoting or resisting particular strategies for responding to such purported problems; and (3) determining to what vision of the future change efforts should be directed.

As with the 1970s and 1980s (the two dates of Erickson's publication), ours is also a rime when anthropologists of education are far more likely to be housed in faculties of education than in anthropology. Peripheral then to its disciplinary home in anthropology (although consistent with the anthropology of policy more generally (e.g., Shore and Wright, 1997; Wedel et al., 2005)), the anthropology of educational policy implementation must compete with the dominant paradigm for policy research in education. As Levin- 
son and Sutton assert (2001), this dominant paradigm, which we refer to as the "technical-rational approach," takes a narrower, more formal, and primarily instrumental view of policy; it assumes a neat distinction between policy and practice and often a linear, unidirectional relationship between them; it attempts to apply positivistic principles and methods from the natural sciences to explain and predict educational policy processes; it takes for granted received categories (such as "academic achievement" or "English language learner"); and it seeks certain actionable truths embodied in purportedly value-free scientific studies.

As we shall see, anthropological studies of educational policy implementation, by contrast, define policy itself much more broadly, and consequently include a broader range of social actors in their analyses; they problematize clean distinctions between policy formation and implementation, or appropriation; they aim for interpretation rather than explanation and prediction; they question received categories; and they attempt to persuade with clear and compelling arguments while critiquing other fields' promises to deliver "objective" truths (for further discussion of this contrast, see Rosen, 2009). Erickson's central argument is "that ethnography should be considered a deliberate inquiry process guided by a point of view, rather than a reporting process guided by a standard technique or set of techniques, or a totally intuitive process that does not involve reflection" (1984: 51). Likewise, there is no single way to conduct the anthropology of educational policy implementation, but such work does entail a particular lens or perspective on policy processes. As we elaborate below, this starts with questioning the conventional definitions of both policy and practice and broadening the unit of analysis for policy implementation studies.

\section{Defining the social unit for anthropological studies of educational policy implementation}

Using Bronislaw Malinowski's (1922) classic ethnography of a Trobriand Islands village as the exemplar, Erickson's (1984) essay considers how the ethnography of schooling is and is not like classic ethnography. He concludes that many general principles of classic ethnography apply readily to the ethnography of schooling, but that the specific methods must differ because the units of analysis for the two enterprises differ in fundamental ways:

An American school is not a Trobriand village. There may be points of analogy between the
two, but there are many points at which the analogy breaks down. For example, the village
involves the life of its members 24 hours a day over many generations; the school does not
.. But we can identify the general principles for doing the ethnography of a primitive village
[and] we can try to identify which of these general principles still apply when one turns to
the ethnography of a school - a partial community whose members (ideally) hold achieved
statuses, in which rights and obligations are not reciprocal, in which the goods and services
exchanged differ markedly in kind, and in which knowledge is nontraditional and rapidly
changing. (1984: 53-54)

The anthropology of educational policy implementation is built around analysis of a social unit even more amorphous than a school (schools are at least bounded geograph- 
ically). What is this unit of analysis? To answer this question, we first consider how mainstream (technical-rational) policy research defines the unit of analysis for education policy research, and then contrast this with how anthropological studies approach this same task.

Technical-rational studies of educational policy use an input-output model where the "treatment," or policy, is presumed to be known, and the main subject of concern is outcomes (e.g., test scores). Per this framing, what the policy is is not so much in question as what the policy does (and here too analysis is often limited to indicators related to what the policy is supposed to do). This way of defining the unit of analysis relies upon and takes for granted conventional definitions of both policy and practice. According to these received notions, policies are formal institutional products (the plans formulated by officially recognized policymakers such as school board members, commissioners of education, and political leaders), while implementation, or practice, is the activity of those charged with putting these plans into action (such as teachers and principals). For example, elected officials make policy, while teachers and principals engage in practice. This presumption of a clean divide between policy and practice - and likewise between policy creators and policy enactors - naturally leads conventional policy implementation scholars to exclude the former half of each pair from the unit of analysis for their studies, while the latter are often scrutinized for the fidelity of their implementation in relation to the original design.

This way of defining the unit of analysis for educational policy studies may appear to be commonsensical and, as such, unproblematic. However, from an anthropological perspective, it is its commonsensical nature that is precisely the problem, because the dependency on everyday understandings of both policy and practice causes conventional studies to miss (or misconstrue) important aspects of the policy implementation process and exclude or misrepresent key actors and phenomena from their analyses. Anthropological studies of policy implementation challenge the neat, common-sense distinction between policy and practice, or between policy formation and policy implementation, even while they cannot fully escape these terms and the conventional understandings they embed. It is not that these traditional definitions are necessarily or entirely wrong - who can argue that elected officials make policy? - but rather that they are conceptually inadequate or incomplete. As sociocultural theorists remind us, planning, or policy-making, necessarily includes doing (i.e., what is conventionally considered practice), while implementing necessarily involves planning as well as creating, adapting, and/or (re)ordering strategies for solving problems (i.e., what is conventionally considered policy). Levinson, Sutton, and Winstead (2009) emphasize "appropriation," the idea that implementers can take over the determination of what gets implemented and thus that policy as practiced cannot be understood absent this consideration. Phrased another way, leading is not restricted to the leaders and doing is not exclusively the province of implementers; although they do not all have the same degree of formal authority, they are all involved in a web of interconnected social activity.

However, while anthropologists of educational policy implementation challenge these conventional definitions, the subfield has not as yet invented any new or more precise vocabulary. Consequently, anthropologically oriented policy researchers employ conventional terminology, sometimes with qualifying adjectives like "authorized policy" 
and "state policy" (e.g., Levinson and Sutton, 2001: 4, emphasis added). Indeed, anthropologists often use conventional definitions as a point of departure (see Anderson, 2009; Kendall, in press; Koyama, 2010), but also embrace an alternative, more democratic understanding of policy that blurs the neat distinction between policy and practice characteristic of conventional studies (see Levinson and Sutton, 2001, and Levinson, Sutton, and Winstead, 2009). According to this alternative anthropological definition, educational policy is a form of sociocultural practice that involves efforts by a range of actors with varying degrees of formal role authority to: (1) define what is problematic in education; (2) shape interpretations and means of how problems should be resolved; and (3) determine to what vision of the future change efforts should be directed. This broader conception of policy directs attention to the social and cultural processes of interpretation, contestation, adaptation, compromise, and sometimes resistance that shape all points on what would be conventionally understood as the continuum between policy and practice. It also directs attention to the diversity and inter-connectedness of actors involved in these processes. This anthropological understanding of policy finds echo in Erickson's (1984) original piece, as Erickson acknowledges that not all members of the partial community of school will bring the same understanding to an issue, nor will members of the social unit share in the ways they use and relate to the physical space in question (i.e., for Erickson, the school).

Anthropological studies of policy implementation illuminate the socially constructed nature of each of the above interrelated dimensions of policy (problem definition, strategies of problem resolution, and larger moral worldview). For example, such studies examine the social and cultural processes that frame why an extant reality is viewed as problematic by those being studied (the problem diagnosis), what strategies of action those being studied understand as available for response (i.e., the tools, vehicles, and means of social action), and what they think a "better" outcome would look like and entail. This perspective asserts that not only policy solutions but also the purported "problems" to which policies are ostensibly addressed are the product of social and cultural processes rather than natural or objective "facts" (see Rosen, 2009: 276). Juxtaposing the emic and the etic, the anthropologist endeavors to describe the various stances of actors involved in the policy implementation, but also reserves an external analytic voice. For example, Rosen (2001) shows how, as a consequence of social processes that gave meaning to intrinsically ambiguous conditions, a local school board in the midst of California's "math wars" constructed the problem of mathematics achievement in the district as one of curriculum rather than of teacher training or expertise. This construction of the problem suited school board members' need for a relatively simple explanation that avoided nettlesome questions of teacher capacity, reduced the complexity of the situation, and was amenable to a relatively simple, technical, and cost-effective response (regardless of whether those external to the situation would understand the response as a solution or as something else). Differentiating her own understanding from those she studied, Rosen explains how those engaged in math reform pursued their task and according to what logics, but she also adds her own interpretation.

Given their broader definition of policy as a form of sociocultural practice, the unit of analysis for anthropological studies of policy implementation is considerably broader than in conventional research and varies from study to study, depending on the question 
a particular project aims to answer or explore. This means that anthropologists often include more diverse kinds of actors in their studies of policy implementation (e.g., not only formally recognized policymakers and implementers, but also students, parents, and entities such as professional school reform or advocacy organizations who shape the implementation process), conceptualizing these diverse actors as part of a larger network of interconnected activity. The determination of whom or what should be studied is a function of the anthropologist's analytic judgment: does considering this person help us better understand the research question at hand and the problem diagnoses, strategies, and senses of "what should be" that inform the policy implementation under study? From an anthropological perspective, anyone who significantly shapes one or more of the above three dimensions of policy can be considered a "policy actor," even if they are not an "authorized" policymaker or implementer. Moreover, adherence to the anthropological principle of holism (the commitment to considering phenomena in relation to their social context) further requires that anthropological studies examine the social and cultural context (i.e., the systems of social relations, practices, ideas, beliefs, narratives, values, and understandings) that shapes and is shaped by the implementation activity under study. For example, in Rosen's study of the "math wars" described above, the unit of analysis was the people, ideas, and actions that together entailed the math reform effort; this was bigger than just the analysis of the perspective of one or several implementers. The idea was to position readers not just in the shoes of the actors involved in the math wars, but also to have a more holistic understanding about those wars, one that was more expansive than the perspective of any particular actor and which showed the relationship between this particular policy debate and the contexts that both provoked and enfolded it.

Consequently, in anthropological studies of educational policy implementation, geographic coherence is often not a central consideration when drawing the analytic parameters for a study. Indeed, relevant members of the social unit of analysis may live and work in different places, may never come in direct physical contact, and may not even overlap chronologically in terms of when they are involved in the policy implementation being considered. For example, in Hamann's (2003) study of an unlikely partnership between a private Mexican university and two Georgia school districts, "field" research was conducted in Monterrey, Mexico and Atlanta, as well as in the two districts 90 miles from Atlanta. Policy actors included educational consultants based in Washington, DC and Mexico, Georgia-based business and school leaders, a superintendent's secretary, several newspaper reporters, two graduate students at the University of Massachusetts, and more than 40 teachers, about half from Georgia and half from Mexico. All of these actors were connected in a novel effort formally intended to improve school outcomes for a rapidly growing Latino enrollment, but only some would have been traditionally characterized as "official educational policymakers."

Capturing this situated complexity of both understanding and action means the methods of anthropological policy studies may well need to be multiple, various, and not as dependent on direct observation as most anthropological inquiry. The increasingly common multi-site anthropological studies of globalization and population mobility (e.g., Guerra, 1998; Ong, 1999) provide examples of how anthropologists in other subfields have dealt with this challenge. This decoupling of geographic and analytic boundaries also makes possible new insights as a consequence of examining the exchange of ideas 
across time and space. For example, Reed-Danahy's (2003) research shows how educational ideas and strategies are transformed as they become "supranational." AndersonLevitt's (2003) book. Local Meanings, Global Schooling offers a number of strong chapters on how educational ideas imported from elsewhere are transformed in their conversion to local practice. So too, does Sutton and Levinson's book (2001). Likewise, in a discussion of civic education in Mexican secundarias (middle schools), Levinson (2005) notes historic French, German, and American influences that shape such a curriculum, as well as contemporary national influences as diverse as Switzerland, Argentina, and Japan (see also Dietz and Mateos Cortes, 2011).

\section{Malinowski's (and Erickson's) categories of analysis}

With the unit of analysis for anthropological policy implementation studies defined, we return to Erickson (1984), using his essay to elaborate the conceptual basis for the broader understanding of policy we have articulated. Erickson directs much of his essay to considering the applicability of Malinowski's various categories of analysis - social organization, exchange, belief systems, myth, folk philosophy, and ritual - to the ethnography of schooling. Here we do the same, applying Malinowski's categories to the context of educational policy implementation. Our purpose is to illustrate what an anthropological perspective offers to this domain. Malinowski's categories may at first seem anachronistic and to have been supplanted in contemporary studies by the questions of power, ideology, identity, discourse, and so forth to which Shore and Wright (1997) refer in the epigraph that starts this chapter. For example, a chief concern of contemporary anthropological studies of educational policy implementation is how policy activity (i.e., the actions of the full range of actors described previously) both shapes and is shaped by systemic inequalities related to gender, social class, and race: such as how educational policy in the United States reflects and reinforces belief in meritocracy and individual effort as the route to social mobility and how this helps reproduce such systemic inequalities. However, the distance between these older and newer sets of analytic categories may not be as vast as it first appears. Underlying each is an enduring concern with the problem of social order, especially the construction, maintenance, and function of systems of social relations, thought, and belief. Consequently, while the study of power has become more overt and purposeful (Nader, 1972) and there have been other important theoretical developments since Malinowski, his categories suit our purpose because they represent the conceptual building blocks and long-standing concerns of the field.

The first category Erickson considers, social organization, may fit the anthropology of educational policy implementation even better than the ethnography of schooling. Erickson writes, "As a way of thinking about the school as a small community, we could apply to it the fundamental terms of discourse about social organization - person, status, role, rights, obligations - taking very little for granted initially" (1984: 54). Processes of educational policy implementation also link people, invoking statuses and roles with attendant rights and obligations. For example, a study by Hamann and Lane (2004) focused on state department of education employees in Puerto Rico and Maine, who were intermediaries in the process of converting the federal Comprehensive School Reform 
Demonstration (CSRD) process into actual school practice. In this instance, the people being studied were defined by their status in the hierarchy between federal resources and local practice and their roles as professional educational bureaucrats (as opposed to other roles these people no doubt played in other facets of their lives, like spouse, parent, sports fan, etc.). They "performed" their status in part by direct and indirect interaction with those of other statuses (e.g., organizing professional development workshops for funded schools, or attending US Department of Education workshops) and through this performance helped reshape what the policy was "as delivered" - making CSRD a "high school-only" initiative in Maine, for example, or supporting the inclusion of the Puerto Rico State Systemic Initiative (PRSSI) as an authorized whole-school change model, even though until that point it was mainly a science education reform strategy. By paying attention to the social organization of policy implementation, the researchers found and studied a source of policy development that would have been neither identified nor analyzed in a traditional study because the individuals in question were not official policymakers. However, their roles as intermediaries gave them substantial influence over the implementation of federal policy.

Erickson next recounts Malinowski's analysis of social behavior as a form of exchange, in which individuals trade unlike goods (emphasis in Erickson, 1984: 54). To illustrate such relations and practices at school, Erickson describes students exchanging deference to their teachers for kind treatment. In educational policy implementation, we might identify the exchange of extra attention and resources from a curriculum developer with a site willing to pilot its curriculum. For example, the developers of the AVID high school reform model exchange high levels of their own professional assistance to pilot school sites that are willing to implement their school improvement model, but also be extensively documented (Datnow, Hubbard, and Mehan, 2002; Mehan et al., 1996). In the study of educational policy implementation, the anthropologist needs to explain the diverse motivations and interests driving different categories of actors (such as designers of a school reform model as compared with educators at prospective implementation sites) to participate in policy implementation. AVID designers needed pilot sites to test and refine their ideas about how to improve high schools for a broader range of students. For personnel at prospective pilot sites, external scrutiny (which could reveal that not all students are being well served) might be a turn off to participation. However, the prospect of extra resources, expert guidance, and "help" entailed in AVID's offer to support a reform effort might be enough to overcome scrutiny-related reluctance. Model developers and site personnel do not need to fully agree on the problem to be solved, nor on the strategies of implementation, to cooperate on implementation. Exchange then explains a reason for the collaboration across difference that is intrinsic to policy implementation.

Malinowski and Erickson's third category is belief systems, which Erickson subtitles "Religion, Folk Philosophy, and Ritual." Erickson explains: "The school can be seen as having a worldview or ideology ... grounded in folk philosophy whose elements are: terms of definition, principles of valuation, rules of logic, methods of explanation for cause, and forms of predictive statements" (1984: 55). It is not difficult to identify such elements in educational policy implementation as well. Labels that describe various kinds of students - for example, the racial/ethnic, language status, socioeconomic, and special education labels formalized as data categories in the United States' No Child Left Behind 
Act (NCLB) and elsewhere - clearly act as terms of definition with clear implications for placement, assessment, and other interaction. NCLB and the recent standards movement can readily be understood as embedding principles of valuation (what knowledge matters in each of the disciplines, which disciplines should be covered in "high stakes testing," etc.) and reflecting key articles of cultural faith, especially belief in the possibility via science and evidence-based practice - of obtaining unambiguous knowledge about educational processes and controlling educational outcomes via technical-rational policy activity. Indeed, the latter is a fundamental belief underlying nearly all formal educational policy activity (see Rosen, 2009).

The policy implementation process also embeds various rules of logic - for example, that textbooks should be a source of curriculum content, that classrooms should be led by a single educator instead of teacher teams, or that school funding should be supported by a hybrid of local, state, and federal revenues (the norm in the United States) or just by the federal government (as is common in Mexico and many other countries). Heath (1983) writes memorably about the language development "logic" of early elementary education in the late 1970s US South, where the reading curriculum was ordered from phonetics, to grammar, to creative composition (and thus failed to be immediately responsive to the working-class African American children of the neighborhood of Trackton, who had been socialized in an environment that prized creative exaggeration). In other words, the logic of curriculum policy implementation in that instance seemed so "logical" and unexceptional that its poor fit for a whole segment of students was unrecognized. Rules of logic impede other ways of thinking about how policy should be implemented; they define a normal way of operating. Finally, it is easy to identify predictive premises in policy implementation efforts. Indeed, that is the point of formal policy implementation: The belief is if $x$ strategies are pursued, $y$ new social reality will ensue.

While one could argue that myth - Malinowski's fourth category - is a kind of belief system (his third category), to stay true to Malinowski and Erickson's taxonomy, we consider myth as a fourth category here. Erickson offers examples of myths that are common in American curricular content - e.g., "Creation Myths: The Coming of the Pilgrims, The Revolutionary War, The Opening of the West, The Civil War, The Rise in the Standard of Living" (1984: 55, capitalizations original). Anthropologists use the concept of myth to indicate socially constructed narratives that give meaning and order to human experience by providing relatively simple and reassuring explanations for ambiguous, complex, and/or troubling circumstances. These stories often reflect, validate, and reinforce a society's "sacred beliefs": those cherished ideals and values that are accepted without question and taken on faith, such as the American achievement ideology and the faith in science and rational policy activity previously noted. Although in popular usage myth implies falsehood, the central consideration in the anthropological analysis of myth is not a question of empirical accuracy per se, but rather how such stories function to help individuals make sense of social conditions and justify particular actions. As such, the concept of myth reflects a particular stance on reality itself: the premise that reality is intrinsically ambiguous and all explanations of it are necessarily selective and incomplete (see Rosen, 2001, 2009).

In our work with schools, we have both encountered the myth, or story, of the old man on the morning beach who was methodically throwing one starfish after the next 
back into the surf, lest they be stranded above the tide line and die of dehydration. Confronted by a younger person who tells the old man that what he is doing does not matter, that he cannot possibly save all the stranded starfish, the old man looks at the starfish in his hand (about to be rescued) and says, "It matters to this one." A version of this story was repeated on a poster that hung in the Center for Urban Ethnography at the University of Pennsylvania's Graduate School of Education in the mid-1990s. Nebraska's long-time Commissioner of Education, Doug Christiansen, who retired in 2008, used to wear a gold starfish on his lapel and distribute similar starfish pins to educators across the state with the purpose of invoking this story. In both settings, the message and analogy to education was overt: our efforts matter to this one. It is easy to see this as a "feel-good" myth, one that recommits us to making sure schooling matters for one child, if only that one. But it is also useful to see how this myth steers thought patterns and conceptualizations of what is possible. Subtly, this myth challenges another - that all students can reasonably be expected to achieve to high standards - as it concedes that most starfish will not make it. As such, it expresses the tacit acceptance of inequality that is a fundamental element of capitalist societies. It frames starfish, and students, as without agency (they need to be rescued). And, reflecting the atomistic view of social order that goes along with US individualism, it celebrates individual quixotic effort (the old man's efforts are better than doing nothing), but in so doing steers away from a more systemic critique or solution: why are so many starfish imperiled?; what systemic solution could improve the fates of more of them? Returning overtly to the elements of policy and policy implementation, this myth defines the problem (vulnerable starfish), celebrates a strategy of response (the heroic rescue of at least a few starfish by a single old man), and defines a "better" social reality (in which not quite so many vulnerable starfish perish).

Of course, myths are not policies by either the conventional understanding of policy or the adapted one that emerges from the anthropology of educational policy implementation. But there is a structural parallel and an intertwining between myth (as anthropologically understood) and both what comes to pass educationally and how it is understood by those linked across a hierarchical policy implementation process. Myth may provide a key "glue" that aligns both efforts and rationales of those who are differently situated in relation to implementation. When the Commissioner repeats the starfish rescue story at a state conference and an attending principal and teacher both nod in assent, that solidarity informs how more concrete suggestions for practice are heard and responded to. It may suggest that Commissioner and school-based practitioner alike see extra individual effort by educators (akin to the old man) and exceptional successful outcomes for at least a few (akin to the rescued starfish) as at least part of what successful implementation should look like. In that sense, myth gets inexorably incorporated into policy as practice.

Erickson returns to folk philosophy as the fifth of Malinowski's categories that he considers. He writes, "The varying folk philosophies (metaphysics, epistemology, logic, ethics) inherent in teacher culture, administrator culture, and student culture may provide cultural lenses through which the same events look different" (1984: 55). He then goes on to suggest that folk philosophic systems are composed of three elements: basic terms, relations between basic terms (which he calls "basic premises"), and relations between terms and premises that are manifest in statements of correlation/probability, causal explana- 
tion, and prediction. The anthropology of educational policy implementation could readily use the same taxonomy, identifying teachers' and administrators' use of basic terms, like "adolescent literacy," "grade-level," and "reader" to build a basic premise such as: secondary school students who are behind grade level need intentional educational interventions that are describable within a category called adolescent literacy. In turn, the belief systems of implementers of such a program could be examined to see if they concurred with the causal explanation of literacy as a missing educational component or the prediction that overtly attending to it would remedy the identified problem. In this example, the folk philosophies of various kinds of stakeholders could be juxtaposed. Presumably, secondary-school students targeted by such an initiative might dislike the premise that they needed a literacy program since, to them, that basic term would invite a range of unpalatable connotations about academic weaknesses. Similarly, private schools with partially public enrollments (common in parts of New England) might resist offering adolescent literacy initiatives, fearing that literacy education at the secondary level would suggest that they have academically weak students rather than strong ones. Yet certain teachers might gravitate to this premise, finding it an apt explanation for a range of students' struggles that they have witnessed and tried to attend to in their careers (Hamann and Meltzer, 2005).

As with myth, folk philosophy can become implicated in policy implementation through purposeful application. Folk philosophies (which can vary widely and change over time) are in Erickson's rendering variable yet enduring characteristics of educational systems. As such, folk philosophies become building blocks not only for educational policy implementation (informing problem diagnoses, strategies, and the sense of "what should be"), but also for routine practice. So it is the task of the anthropologist of educational policy implementation to determine whether examining educators' invocation of folk philosophies is helpful for understanding the process of implementation in a particular case. As Erickson notes, part of the anthropologist's work is to interpret - to reduce complex intertwining practices and imperatives into an intelligible and, ideally, illuminating account. Often, identifying the folk philosophies that inform implementation serves as a useful interpretive move.

The sixth Malinowskian category Erickson directs us to is ritual. Rituals generally consist of stylized or formalized activity that, by means of predictable scripts for behavior, help produce and maintain social order, conveying symbolic messages that reinforce sacred beliefs, legitimate existing social arrangements, and help manufacture or elicit feelings of social solidarity and individual belonging to a larger collective. Erickson offers recitation of the Pledge of Allegiance and the awarding of varsity athletic letters as examples of rituals. Policy implementation can also be viewed through this lens. Symbolic activities such as myth and ritual often involve a degree of what critical theorists call mystification: symbolic representation of the social order in ways that differ systematically from the reality on the ground. For example, at their most fundamental level, many of the activities that comprise formal policy-making can be understood as symbolic reassurances that our idealized beliefs about how government works (e.g., government of, by, and for the people) are actually true. Thus, even when policy events serve little instrumental function (such as when public hearings on this or that issue have little actual bearing on policy decisions), they nonetheless perform the important expressive function of validating this core belief (see Rosen, 2001, 2009). 


\section{Ensuring the reliability and validity of anthropological policy studies}

Of course, schools are more than the sum of social organization, quasi-economic exchanges, belief systems, myths, folk philosophies, and rituals. Moreover, as Erickson notes, by calling outsize attention to facets of the quotidian, anthropologists invariably distort social realities (1984: 58). Details are left out, so that readers can concentrate on the ones the anthropologist hopes to draw attention to. Invariably, these decisions, however expert and defensible, represent a point of view. The anthropologist chooses to offer this depiction of the social reality that he or she recorded, instead of the myriad other depictions that would have been possible. So too does the anthropological analysis of educational policy reflect the point of view of the anthropologist, drawing attention to certain facets of the policy implementation under study and thereby steering attention away from other aspects. As critical realists would note, all research arguably involves such processes of selection, representation, and thus inevitable distortion, but anthropological studies - whether school ethnographies or policy analyses - are particularly vulnerable to charges of bias because of their reliance on the individual anthropologist's powers of interpretation and, in Erickson's view, the lack of explicit "rules of evidence" for evaluating their validity. To protect against such charges, Erickson suggests six questions that he argues should be asked of every ethnography:

How did you arrive at your overall point of view?

What did you leave out and what did you leave in?

What was your rationale for selection?

From the universe of behavior available to you, how much did you monitor?

Why did you monitor behavior in some situations and not in others?

What grounds do you have for determining meaning from the actors' point of view? (1984: 58-59)

These same questions suggest a framework for evaluating and strengthening the validity of anthropologically oriented policy studies as well. They ask the researcher to make his or her point of view overt, present the evidence grounding assertions of emic (and etic) viewpoints, and reflect explicitly on the processes of selection and interpretation that inevitably shaped the study:

I believe that a good ethnography should not only be able to answer those questions, but should provide data to illustrate the decisions made during the research process ... In other words, the ethnographer should provide readers with guidelines for the falsification of the analysis, should a reader decide to replicate the study ... The positivists have a point. Although I may object to their particular rules of evidence, I am forced to admit that some systematic rules of evidence are necessary. (1984: 59)

Erickson then offers some rules of evidence for school ethnography, several of which would clearly also apply to the anthropology of educational policy implementation. For example, he notes that schools are embedded in larger social systems (just as educational policy implementation is embedded in larger social and policy universes), and invariably that means that more data could hypothetically be collected than is realistic or fea- 
sible. This requires explicit strategies for "eliminating some of the welter of information" (1984: 60). These include explaining how the social unit of analysis came to be denned and bounded, how the sample was selected, how researchable questions were identified and operationalized, and how holism (the anthropological commitment to considering phenomena in relation to their social context), though necessarily checked, was not abandoned.

As part of this consideration of rules of evidence, Erickson takes on the core tool of anthropological analysis - the anthropologist - and emphasizes that tool's invariable subjectivity. In so doing, he also suggests a key criterion for evaluating the quality of ethnographic or anthropological studies: the researcher's clarity in communicating his or her particular point of view as a subject.

It was I who was there doing the fieldwork, not somebody else. My fundamental assumptions and prejudices are part of my me. I cannot leave them at home when I enter a site. I must study a place as me ... The desirable goal is not the impossible one of my disembodied objectivity (I am a subject, not an object) but of clarity in communicating my point of view as a subject, both to myself and to my audience. In addition to being me to my audience, as an ethnographer I have an obligation to have been there. Really being there means experiencing strong relationships with whomever else is there (one's informants). Some of these relationships may feel good and others may hurt. ... [I]t is not involvement at arm's length." (1984: 60-61, emphasis original)

It follows that in an anthropology of educational policy implementation, the anthropologist needs to name who he or she was in relation to the policy implementation under examination. In Hamann's (2003) work in Georgia, that includes documenting a role of exchanging successful Tide VII grant-writing (for us\$ 500,000, for Systemwide Bilingual Education) for access to a demographically fast-changing school district that was partnering with a Mexican university to negotiate that change, and for which the us\$ 500,000 grant was one of several important funding sources. That grant-writing role was informed by a sense of what should be (which was proposed in the grant), and meant access to certain individuals (the leaders of the binational partnership) more than others (e.g., the newcomer immigrant students for whom the partnership was ostensibly created). The reason this account of a multifaceted partnership could be shared was because the researcher was there, and the way it was shared, in turn, reflects who that researcher was (subjectively) as well as what he saw and paid attention to or may have missed.

Yet that account of educational policy creation and implementation in Georgia required not just documenting who the anthropologist was in relation to the data collection and analysis task (as important as those are). As Erickson consistently implies, there is a there that the anthropologist is trying to chronicle and the anthropologist's account is not just a product of point of view, but also of what was there to be seen. Complementing Erickson's recommendations related to anthropological evidence, we thus also think it important that anthropological renderings of educational policy implementation account for what Maxwell (1992) has characterized as the validity of qualitative data. Acknowledging that educational research, including anthropological research, is intrinsically interested should not stop anthropologists from trying to make accurate accounts of what transpired and how what transpired is/was understood. 
As with the terms "policy" and "practice," anthropologists face dilemmas when using a term like validity, which has such ingrained and common usage in more positivistic domains of educational research. Yet Maxwell (1992) asserts that this term can be used to consider data like that which anthropologists of education and educational policy implementation would normally collect, because we can ask about the correspondence between what was collected/measured and what could have been collected/measured. In Maxwell's rendering, there are five levels of validity that can be considered in qualitative research: descriptive, interpretive, theoretical, generalizability, and evaluative. These five offer an additional taxonomy that can both guide anthropologists of educational policy implementation as well as those who read such anthropologists' accounts.

Descriptive validity refers to factual assertions made by the researcher. If a researcher records that Malawi received money to expand primary education (Kendall, in press), then a descriptive validity check would ask, "Did it?" What's the proof of such a transfer? Interpretive validity refers to the accurate portrayal of the interpretations of those under study. As an interpretive validity check, if an anthropologist asserted that most teachers in a site expressed skepticism of No Child Left Behind, then the checker can examine the evidence for such a claim (e.g., recorded frequent complaints about this act in faculty lounge teacher conversations).

The remaining three types of validity differ from the first two in that they are not "experience near" (Maxwell, citing Geertz [1974], 1992: 291), but rather characterize the researcher's assertions. As an example of theoretical assertion. Maxwell suggests a researcher understanding a student's throwing of an eraser as an act of resistance. In turn, the validity check for such an assertion would be an examination of the supporting evidence for that claim: Did the student have reason to resist?; Is it a reasonable understanding of the classroom environment to assert that eraser throwing would not be welcome?; and so on. Generalizability refers to "the extent to which one can extend the account of a particular situation or population to other persons, times, or settings, than those directly studied" (1992: 293). Anderson (2009) tries to expand the generalizability other account by comparing her fieldwork on the politics of language education in California in the mid-1990s to her view on the politics of language education in Georgia where she has lived and worked subsequently. Her claim for the broader relevance, or generalizability, of her studies in California to other sites is advanced by her invoking the different case of Georgia. If readers agree that lessons from California are relevant to Georgia (and/or vice versa), then Anderson's quest for generalizability is advanced. Indeed, per the logic of maximum variation sampling (Patton, 1990), if Anderson can highlight both how different California and Georgia are and, yet, how the case of one is still relevant to the other, then her quest for generalizability is advanced even further.

Evaluative validity measures the aptness of applications of evaluative frameworks. Evaluative frameworks in this instance refer to overtly subjective judgments on the part of the researcher. So if a researcher claims that a policy was unjust or mean, the validity check would examine the evidence in relation to a broader understanding of what constitutes injustice or meanness. Given contemporary interest on the part of many anthropologists of education to question the justice of educational policy implementation (e.g., Abu el-Haj, 2006; Gilmore, 2008; Ladson-Billings, 2006; Lomawaima and McCarty, 2006), successful assertion of evaluative validity becomes an important concern. 


\section{A heuristic for future studies}

Using and adapting Erickson (1984) and adding Maxwell (1992), we have attempted not simply to define the anthropology of educational policy implementation, but also to offer a heuristic that can guide novice or aspiring contributors to the field. Specifically, we propose that anthropological studies of educational policy implementation should aim to accomplish particular analytic ends. First, they should make explicit the social unit of analysis and the rationale for how the anthropologist has drawn its boundaries: what is/ are the educational policy(ies) whose implementation is being investigated?; what are the constituent pieces in terms of problem diagnosis, strategies of resolution, and sense of what should be that are embedded in that policy?; who are the actors the anthropologist has chosen to include in the analysis and why? Second, they should overtly address the tension in how they understand policy versus how it is conventionally understood (a step that will likely be necessary until anthropology has a larger, better recognized role in educational policy implementation studies, and/or it has invented new technical terms to distinguish its conception of policy from the conventional definition). Third, they should illuminate, from both emic and etic perspectives, the chain of human relationships that is created through the implementation of a formal or informal educational policy. This includes shedding light on the social and cultural processes in which policies are implicated - an analytic task for which Malinowski's categories of social organization, exchange, belief systems, myth, folk philosophy, and ritual can provide a useful rubric or frame. In so doing, they should examine the prevailing understandings and intentions informing policy activity. Finally, anthropologists should explicitly acknowledge the intrinsic distortion that is the inevitable product of their research write-up and their stance (what Erickson refers to as "point of view"), and still provide readers grounds for evaluating the validity of their account (per Maxwell).

Traditional educational policy studies too readily ignore important dynamics that can broadly explain both how educational systems operate and why they yield the outcomes they do. By contrast, sociocultural approaches capture and highlight important data that these traditional studies miss. Fortunately, it is steadily becoming more widely recognized that anthropological approaches have a keen role to play in the study of educational policy implementation (whether the anthropological approach is overtly noted or not). And only through more nuanced and thorough understandings of what is happening can we make informed choices about how to generate more favorable practices and outcomes.

\section{References}

Abu el-Haj, Thea

2006 Elusive Justice: Wrestling with Difference and Educational Equity in Everyday Practice. New York: Routledge-Taylor \& Francis.

Anderson, Kimberly S.

2009 War or Common Cause?: A Critical Ethnography of Language Education Policy, Race, and Cultural Citizenship. Charlotte, NC: InfoAge Press.

Anderson-Levitt, Kathryn, ed.

2003 Local Meanings, Global Schooling: Anthropology and World Culture Theory. New York: Palgrave Macmillan. 
Datnow, Amanda, Lea Hubbard, and Hugh Mehan

2002 Extending Education Reform: From One School to Many. London: Routledge Farmer.

Datnow, Amanda and Vicki Park

2009 Conceptualizing Policy Implementation: Large-Scale Reform in an Era of Complexity. In Handbook of Education Policy Research. Gary Sykes, Barbara Schneider, and David N. Plank, eds. Pp. 348-361. New York: Routledge.

Dietz, Gunther, and Laura Selene Mateos Cortés

2011 Multiculturalism and Intercultural Education Facing the Anthropology of Education. In A Companion to the Anthropology of Education. Bradley A. U. Levinson and Mica Pollock, eds. Pp. 495-516. Chichester: Wiley-Blackwell.

Erickson, Frederick

1984[1973] What Makes School Ethnography "Ethnographic"? Anthropology and Education Quarterly 15:51-66.

Erickson, Frederick, and Kris Gutierrez

2002 Culture, Rigor, and Science in Educational Research. Educational Researcher 31(8):21-24.

Gilmore, Perry

2008 Engagement on the Backroads: Insights for Anthropology and Education. AnthropolGuerra, Juan ogy and Education Quarterly 39(2):109-116.

1998 Close to Home: Oral and Literate Practices in a Transnational Mexicano Community. New York: Teachers College Press.

Gutierrez, Kris and Barbara Rogoff

2003 Cultural Ways of Learning: Individual Traits or Repertoires of Practice. Educational Researcher 32(5):19-25.

Hamann, Edmund T.

2003 The Educational Welcome of Latinos in the New South. Westport, CT: Praeger.

Hamann, Edmund T. and Brett Lane

2004 The Roles of State Departments of Education as Policy Intermediaries: Two Cases. Educational Policy 18(3):426-455.

Hamann, Edmund T., and Julie Meltzer

2005 Multi-Party Mobilization for Adolescent Literacy in a Rural Area: A Case Study of Policy Development and Collaboration. Providence, RI: Education Alliance at Brown University, available at

Heath, Shirley Brice http:/ / www.alliance.brown.edu/db/ea catalog.php? >search calc $=\mathrm{d} 10429$

1983 Ways With Words: Language, Life, and Work in Communities and Classrooms. Cambridge: Cambridge University Press.

Honig, Meredith, ed.

2006 New Directions in Education Policy Implementation. Albany, NY: SUNY Press.

Kendall, Nancy

In press Global Policies in Practice: Unintended Consequences of International Educational Koyama, Jill P. Efforts to Democratize and Develop the World. Charlotte, NC: InfoAge Press.

2010 Making Failure Pay: For-Profit Tutoring Companies, High-Stakes Testing, and Public Schools. Chicago, IL: University of Chicago Press.

Ladson-Billings, Gloria

2006 It's Not the Culture of Poverty, It's the Poverty of Culture: The Problem with Teacher Education. Anthropology and Education Quarterly 37(2 ):104-109.

Levinson, Bradley A. U.

2005 Programs for Democratic Citizenship in Mexico's Ministry of Education: Local Appropriations of Global Cultural Flows. Indiana Journal of Global Legal Studies 12(1):251-284.

Levinson, Bradley A. U., and Margaret Sutton

2001 Policy as/in Practice: Developing a Sociocultural Approach to the Study of Educational 
Policy. In Policy as Practice: Toward a Comparative Sociocultural Analysis of Educational Policy. Margaret Sutton and Bradley A. U. Levinson, eds. Pp. 1-22. Westport, CT: Ablex.

Levinson, Bradley A. U., Margaret Sutton, and Teresa Winstead

2009 Education Policy as a Practice of Power: Theoretical Tools, Ethnographic Methods, Democratic Options. Educational Policy 2 3(6): 767-79 5.

Lomawaima, Tsianina, and Teresa L. McCarty

2006 To Remain an Indian: Lessons in Democracy from a Century of Native American Education. New York: Teachers College Press.

Malinowski, Bronislaw

1922 Argonauts of the Western Pacific: An Account of Native Enterprise and Adventure in the Archipelagoes of Melanesian New Guinea. London: Routledge.

Maxwell, Joseph

1992 Understanding and Validity in Qualitative Research. Harvard Educational Review 62(3):279-300.

McLaughlin, Milbrey

1987 Learning from Experience: Lessons from Policy Implementation. Educational Evaluation and Policy Analysis 9(2):171-178.

Mehan, Hugh, Irena Villanueva, Lea Hubbard, and A. Lintz

1996 Constructing School Success: The Consequences of Untracking Low-Achieving Students. Cambridge: Cambridge University Press.

Nader, Laura

1972 Up the Anthropologist - Perspectives Gained from Studying Up. In Reinventing Anthropology. Dell Hymes, ed. Pp. 284-311. New York: Pantheon Books.

Ong, Aihwa

1999 Flexible Citizenship: The Cultural Logics of Transnationality. Durham, NC: Duke University Press.

Orellana, Marjorie Faulstich

2009 Translating Childhoods: Immigrant Youth, Language, and Culture. New Brunswick, NJ: Rutgers University Press.

Patton, Michael Quinn

1990 Qualitative Evaluation and Research Methods. 2nd edition. Newbury Park, CA: Sage.

Reed-Danahay, Deborah

2003 Europeanization and French Primary Education: Local Implications of Supranational Policies. In Local Meanings, Global Schooling: Anthropology and World Culture The-

Rosen, Lisa ory. Kathryn Anderson-Levitt, ed. Pp. 201-218. New York: Palgrave Macmillan.

2001 Myth-Making and Moral Order in a Debate on Mathematics Education Policy. In Policy as Practice: Toward a Comparative Sociocultural Analysis of Educational Policy. Margaret Sutton and Bradley A. Levinson, eds. Pp. 295-316. Westport. CT: Ablex.

2009 Rhetoric and Symbolic Action in the Policy Process. In Handbook of Education Policy Research. Gary Sykes, Barbara Schneider, and David N. Plank, eds. Pp. 267-285. New York: Routledge.

Shore, Cris and Susan Wright, eds.

1997 Anthropology of Policy: Critical Perspectives on Governance and Power. London:

Stein, Sandra Routledge.

2004 The Culture of Education Policy. New York: Teachers College Press.

Sutton, Margaret, and Bradley A. U. Levinson, eds.

2001 Policy as Practice: Toward a Comparative Sociocultural Analysis of Educational Policy. Westport, CT: Ablex.

Wedel, Janine R., Cris Shore, Gregory Feldman, and Stacy Lathrop

2005 Toward an Anthropology of Public Policy. Annals of the American Academy of Political and Social Science 600:30-51. 